\title{
ANALISIS TINDAK TUTUR EKSPRESIF DALAM FILM ANO HI MITA HANA KARYA NISHIURA MASAKI
}

\author{
I.G.B.A. Mulya', G.S. Hermawan², K.E.K. Adnyani ${ }^{3}$ \\ Jurusan Bahasa Asing, Universitas Pendidikan Ganesha, Singaraja \\ e-mail: gede.bj.arta@undiksha.ac.id satya.hermawan@undiksha.ac.id krishna.adnyani@undiksha.ac.id
}

\begin{abstract}
Abstrak
Tujuan penelitian ini adalah menganalisis fungsi dan maksud tindak tutur ekspresif dalam film Ano Hi Mita Hana. Objek penelitian yang digunakan yaitu film Jepang yang berjudul Ano Hi Mita Hana. Penelitian ini merupakan penelitian deskriptif kualitatif dan instrumen utama menggunakan kartu data. Metode pengumpulan data yang digunakan yaitu metode simak dan teknik lanjutan yaitu teknik catat. Dalam menganalisis, menggunakan analisis pragmatik untuk mengkaji penggunaan fungsi dan maksud tindak tutur ekspresif. Teori yang digunakan yaitu teori tindak tutur ekspresif menurut Austin (1965) sedangkan maksud tindak tutur menggunakan teori Searle (1979). Hasil penelitian yang ditemukan terdapat 22 data tindak tutur ekspresif. Terdapat 7 fungsi tindak tutur ekpsresif yang ditemukan yaitu apologies, thank, sympathy, attitudes, greetings, wishes, challenges. Maksud tindak tutur ekspresif yang ditemukan yaitu (1) meminta maaf, (2) terima kasih, (3) penyesalan, (4) mengejek (5) menyalahkan, (6) permohonan, (7) mengharapkan (8) menentang.
\end{abstract}

Kata kunci : pragmatik, tindak tutur ekspresif, maksud tindak tutur

要旨

本研究は、映画『あの日見た花』で使用される特定の目的を持つ会話表現の意味と種類を語用論 を基に明らかにすることである。対象は、映画『あの日見た花』であり、データカードを基にした定 性 的記述研究である。データは、連続視聴から抜粋し、表現の機能と意思を語用論を用いて分析した。表 現理論では、Austin（1965)、表現意思では、Searle（1979)の理論を参考にした。この結果、特定の目的と して使用される表現形式は 22 例あり、意味は 7 例認められた。謝罪、感謝、同情、様態、挨拶、願望の つに分類 7 挑戦にされた。1）ごめんなさい、2）有難う、3）忤い、4）非難、5）誤解 6）㤠願、7）切願望、 8）対すである。

キーワード： 語用論、特定目的表現、表現意思

\section{Pendahuluan}

Dalam lingkungan masyarakat ada berbagai macam kegiatan sosial yang biasa sehari-hari digunakan, salah satunya yaitu kegiatan berkomunikasi. Kegiatan berkomunikasi tidak lepas dari tuturan atau ujaran yang digunakan untuk mengutarakan sesuatu yang ingin disampaikan oleh penutur kepada mitra tutur. Komunikasi dalam penyampaian pesan bahasa tidak hanya melalui kata-kata, namun juga disertai dengan perilaku atau tindakan. 
Tindakan-tindakan yang dilakukan ketika mengucapkan sebuah tuturan atau ujaran disebut dengan tindak tutur. Tindak tutur merupakan tuturan atau ucapan yang mengandung maksud dan tujuan tertentu. Dengan kata lain penutur dan mitra tutur terlibat dalam suatu kegiatan yang berorientasi pada maksud tertentu (Tarigan,1986).

Tindak tutur dapat dikalsifikasikan menjadi beberapa bagian yaitu tindak tutur representatif, tindak tutur direktif, tindak tutur deklaratif, tindak tutur ekspresif dan tindak tutur komisif (Leech 1993), dari berbagai macam tindak tutur tersebut penelitian ini berfokus pada tindak tutur ekspresif. Karena dalam kegiatan komunikasi yang terdapat dapat film ano hi mita hana, banyak terjadi tuturan-tuturan fungsi dan maksud yang merupakan ekspresi dari penutur untuk diungkapkan kepada lawan bicaranya. Penutur biasanya mengungkapkan tuturan dengan ungkapan-ungkapan perasaan yang dimilikinya misalnya mengucapkan dengan maksud menyalahkan, menyindir, mengejek, berterima kasih dan sebagainya.

Berdasarkan penjelasan tersebut, tujuan tuturan ekspresif tidak akan selalu sama dengan apa yang dituturkan oleh penutur, tetapi terkadang berbeda dengan maksud yang sebenarnya ingin disampaikan. Berdasarkan hal tersebut dalam penelitian ini membahas mengenai fungsi dan maksud tindak tutur ekspresif dalam penggunaan penutur bahasa Jepang dalam mengungkapkan tuturan ekspresif kepada mitra tutur. Sehingga dalam penelitian ini mengkaji lebih dalam mengenai fungsi dan maksud tuturan ekspresif dalam film Ano Hi Mita Hana satu kajian pragmatik.

Dalam kaitanya tindak tutur ekspresif, sebelumnya pernah dilakukan penelitian mengenai tindak tutur ekspresif dalam bahasa Jepang oleh Astawa (2013). Pada penelitian Astawa membahas mengenai fungsi dan jenis tindak tutur ekspresif. Tetapi dalam penelitian ini membahas tentang fungsi dan maksud tindak tutur ekspresif. Jenis penelitian ini menggunakan deskriptif kualitatif yang tujuannya untuk menganalisis rumusan masalah berikut ini

1) Apa saja fungsi tindak tutur ekspresif bahasa Jepang yang digunakan dalam film Ano Hi Mita Hana

2) Apa saja maksud tindak tutur ekspresif bahasa Jepang yang terkandung dalam film Ano Hi Mita Hana

Sesuai dengan rumusan masalah diatas, penelitian ini bertujuan untuk menganalisis fungsi dan maksud dalam film Ano Hi Mita Hana. Selain itu, penelitian ini juga bertujuan untuk memberikan wawasan yang lebih luas tentang penggunaan tuturan ekspresif melalui film film Ano Hi Mita Hana.

\section{Pragmatik}

Yule (2006) menyatakan bahwa pragmatik merupakan studi tentang makna yang diungkapkan oleh penutur (penulis) yang kemudian ditafsirkan oleh pendengar (pembaca). Dalam hal ini pragmatik berfokus pada tatanan yang lebih luas karena tujuannya adalah menganalisis mengenai maksud tuturan yang dituturkan oleh penutur kepada mitra tutur bukan hanya menganalisis makna yang terpisah dari kata atau frase dalam tuturan tersebut. Sehingga diperlukan pemahaman maksud yang ingin disampaikan oleh penutur supaya mitra tutur dapat menyimpulkan mengenai apa yang sebenarnya dituturkan agar dapat sampai pada suatu interpretasi.

Pragmatik menurut Koizumi(1993:281) bukanlah bidang yang meneliti atau meninjau aturan penggunaan bahasa. Pragmatik memfokuskan pada masalah ujaran dalam situasi pada penyampaian bahasa. Kalimat sebagai ujaran baru akan memiliki makna yang tepat bila digunakan dalam situasi" 


\section{Tindak tutur}

Searle (1979) membagi tindak tutur menjadi tiga jenis yakni:

(1) Tindak lokusi adalah tindak tutur yang digunakan untuk menyatakan sesuatu atau yang disebut The Act of Saying Something. Jenis tindak tutur ini paling mudah untuk diidentifikasi karena tidak memperhitungkan konteks tuturan.

(2) Tindak ilokusi adalah sebuah tuturan yang memiliki fungsi untuk mengatakan atau menginformasikan sesuatu. Tuturan ini juga dapat digunakan untuk melakukan sesuatu. Tindak tutur ilokusi mempertimbangkan antara siapa penutur dan lawan tutur, kapan dan dimana tindak tutur itu terjadi dan lain sebagainya. Berdasarkan hal tersebut, tuturan ini sulit untuk diidentifikasi. Sehingga tuturan ini merupakan bagian sentral untuk memahami tindak tutur.

(3) Tindak perlokusi adalah tuturan yang diucapkan oleh penutur yang berfungsi untuk memberikan efek atau daya pengaruh terhadap mitra tutur. Efek atau daya pengaruh ini dapat secara sengaja ataupun tidak disengaja.

Sementara itu, menurut Carretero, Marta, dkk (2015) menyatakan tindak tutur ekspresif merupakan salah satu jenis tindak tutur dasar yang diusulkkan yang terdiri dari dua tipe umum yaitu berpusat pada diri sendiri yang berkaitan dengan perasaan pembicara atau penulis dan berpusat pada orang lain yang memusatkan perhatian pada perasaan penerima.

\section{Fungsi Tindak Tutur Ekspresif}

Austin (1965: 150-151) menyebut tindak tutur ekspresif dengan istilah behabitive yaitu sebuah kelompok yang beraneka ragam yang harus dilakukan dengan sikap dan perilaku sosial. Seperti meminta maaf, mengucapkan selamat, memuji, turut berduka cita, mengutuk, dan menantang. Austin mengklasifikasikan behabitif menjadi (a) apologies (permintaan maaf), (b) thank (mengucapkan terimakasih), (c) sympathy (bersimpati), (d) attitudes (menyatakan sikap), (e) greetings (mengucapkan salam), (f) wishes (menyampaikan harapan), (g) challenges (pertentangan (Austin, $1965: 159)$.

1. Apologies (permintaan maaf)

Tipe tindak tutur ini bermaksud untuk mengekspresikan penyesalan penutur karena telah melakukan kesalahan kepada mitra tutur, hal itu dilakukan untuk memenuhi harapan sosial. Namun, tindak tutur tipe ini tidak hanya bermaksud untuk memenuhi harapan sosial saja, tapi juga digunakan penutur sebagai rasa sopan terhadap mitra tutur (Dyah 2015).

2. Thank (mengucapkan terimakasih)

Dalam mengucapkan terimakasih, penutur bermaksud untuk memenuhi harapan sosial bahwa seseorang mengekspresikan rasa terimakasih karena mendapat bantuan atau pertolongan dari orang lain. Terima kasih digunakan untuk rasa mensyukuri atau menerima penghargaan (Marwanti 2013).

3. Sympathy (Rasa simpati)

Pada tipe ini, penutur mengucapkan rasa simpati kepada mitra tutur. Tuturan ekspresif yang termasuk dalam tipe ini yaitu deplore (penyesalan), commiserate (turut berduka cita/bersedih), compliment (pujian), condole (mengucapkan bela sungkawa), congratulate (mengucapkan selamat) dan felicitate (bahagia/senang). Rasa ucapan selamat ekspresif memuji suatu luapan kesan seseorang terhadap suatu hal. 
4. Attitudes (Menyatakan sikap)

Tindak tutur ekspresif yang termasuk dalam tipe ini diantaranya adalah tindak tutur untuk menyatakan sikap, seperti resent (tersinggung/marah), don't mind (tidak keberatan), pay tribute (menghormati/penghargaan), criticize (mengkritik), grumble about (menggerutu), complain of (mengadu/mengeluh), applaud (bertepuk tangan), overlook (memaafkan), commend (berkomentar), deprecate (mencela/memaki), approve (menyetujui/menerima/mengakui), favour (menyukai).

5. Greetings (Mengucapkan salam)

Dalam mengucapkan salam, penutur bermaksud bahwa ujarannya memenuhi harapan sosial bahwa seseorang mengekspresikan rasa senang karena bertemu seseorang. Yang termasuk dalam tipe ini yaitu ucapan salam pertemuan dan perpisahan. Sebagai contoh :

\section{Wishes (Menyampaikan harapan)}

Dalam tipe ini, penutur mengharapkan kepada mitra tutur kebahagiaan atau kesenangan yang akan terjadi di masa mendatang. Yang termasuk dalam tindak tutur ini seperti bless (mendoakan), curse (mengutuk), toast (menyampaikan harapan dengan mengangkat gelas), dan drink to (menyampaikan harapan dengan mendentingkan gelas). Harapan dianggap sebagai rasa digunakan seseorang serta sering digunakan sehari-hari dalam kehidupan di Jepang.

7. Challenges (Pertentangan)

Dalam mengucapkan sesuatu, penutur menolak segala sesuatu yang dikatakan oleh mitra tutur apabila penutur mengekspresikan kurangnya penghargaan pada acknowledgement mitra tutur. Selain itu, maksud tuturan penutur melanggar harapan sosial. Yang termasuk dalam tipe ini seperti dare (menentang), defy (menantang), dan protest (protes).

\section{Maksud Tindak Tutur Ekspresif}

Searle (1979) menyatakan bahwa tuturan ekspresif merupakan bagian dari tindak ilokusi dimana dalam identifikasiannya harus mempertimbangkan konteks tuturan, siapa penutur dan mitra tutur, kapan dan dimana tindak tutur terjadi, serta aspek lainnya yang mempengaruhi tuturan. Searle menjelaskan tindak tutur ekspresif merupakan tindak tutur yang dilakukan dengan maksud agar tuturannya diartikan sebagai evaluasi tentang hal yang disebutkan dalam tuturan untuk mengungkapkan sikap psikologis penutur terhadap suatu keaadan. Tuturan mengucapkan terima kasih, mengucapkan selamat, meminta maaf, menyalahkan, memuji, menyatakan belasungkawa dan sebagainya termasuk ke dalam tindak tutur ekspresif ini.

\section{Metode}

Metode yang digunakan dalam penelitian ini menggunakan metode simak dan metode catat. Dalam penelitian ini yang disimak adalah tuturan totkoh-tokoh yang ada dalam film Ano Hi Mita Hana. Setelah disimak, kemudian dilakukan pencatatan dari data-data yang telah ditemukan. Tahap selanjutnya dilakukan upaya mengelompokkan, menyamakan data yang sama dan membedakan data yang memang berbeda. Dalam mengklasifikasikan data, 
tentu harus berdasarkan pada tujuan penelitian. Adapun yang menjadi tujuan penelitian itu adalah memecahkan masalah yang memang menjadi fokus penelitian.

Dalam penelitian ini, temuan hasil penelitian yang berupa korpus data dari percakapan tokoh-tokoh yang ada pada drama akan dikelompokkan ke dalam jenis dan fungsi tindak tutur ekspresif. Sehingga, dari pengelompokan tersebut akan mempermudah dalam mengembangkan sebuah analisis dari data yang telah diklasifikasikan.Setelah data yang diperoleh dimasukkan dalam tabel klasifikasi data, tahap selanjutnya adalah analisis data. Dalam hal ini metode yang digunakan adalah metode padan pragmatis dan metode agih. Menganalisis dan mengelompokan fungsi dan maksud tindak tutur eskpresif yang sesuai didalamnya.

\section{Hasil dan Pembahasan}

Dalam hasil penelitian tindak tutur ekspresif akan dianalisis secara integral atau menyuluruh, terkait penggunaan fungsi dan maksud tindak tutur ekspresif dalam Ano Hi Mita Hana. Berdasarkan hasil penelitian penggunaan tindak tutur ekspresif dalam film Ano $\mathrm{Hi}$ Mita Hana ditemukan 7 fungsi ekspresif yakni apologies, thank, sympathy, attitudes, greeting, wishes dan challenges maksud tindak tutur yang terdapat didalamnya ada berbagai macam yaitu maksud permintaan maaf ditemukan 2 data, maksud terima kasih ditemukan 1 data, maksud penyesalan ditemukan 2 data, maksud menyalahkan ditemukan 1 data dan mengejek 1 data, maksud permohonan ditemukan 1 data, maksud mengharapkan 2 data dan maksud menentang 1 data.

\section{Fungsi tindak tutur Apologies dengan maksud permintaan maaf}

\section{Data 1}

Menma : まだ私やりない残した事があった皆で、ええとみんな なきや叶えられないお願いだったような気がするんだけど

Mada watashi yari nokoshita koto ga atta mitaide, etto minna de nakyakanaerarenai onegaidatta younaki ga surundakedo

Sepertinya aku sama sekali belum melakukan apa-apa, dan sepertinya itu adalah permohonan yang tidak dapat dipenuhi kecuali dilakukan dengan bersama semuanya

Jintan : みんな

Minaa

Semuanya?

Menma : 超平和バスターズのみんなだよ! !

Chou hiewa basutta no minnadayo

Semua teman kita di super perdamaian

Jintan：知るかよ ツーかなんで俺の前に現れるんだよとっと

消えてくれよ。お前がいるといらないことと思い出してイライラするんだよ。

Shirukayo tsukanande boku no mae ni totto kietekureyo. Omaegairuto ira iranai koto to omoidashite ira ira surundayo

Aku tak tahu tapi kenapa kau muncul dihadapanku. Cepatlah pergi!!. Kalau ada kamu aku bisa mengingat hal-hal yang buruk.

Menma: ごめんね。でもめんままたじんたんに会って嬉しかっよ。じんたん元気そうよかっ 
Gomenne. Demo Menma mata jintan atte ureshikattayo. Jintan genki sou yokatta Maaf ya, tapi Menma senang bertemu dengan Jintan. Syukurlah Jintan baik-baik saja.

Data pada tuturan satu merupakan tindak tutur ekspresif yang bermaksud mengungkapkan permintaan maaf ditinjau dari konteks Menma yang secara tiba-tiba datang kepada Jintan dan mengajukan permohonan. Menma yang melihat Jintan masih merasa tertekan yang membuatnya merasa bersalah karena kematiannya yang membuat Jintan menjadi hikkikomori dan membuat pertemannya menjadi hancur. Fungsi tuturan yang digunakan yaitu Apologies dengan maksud permintaan maaf. Tuturan /gomen/ yang memiliki arti 'maaf' menggunakan modus deklaratif (pernyataan) dan diakhiri dengan nada yang lambat serta suara yang kecil di akhir kalimat sebagai rasa bersalahnya karena setelah mati membuat banyak masalah kepada teman-temannya.

\section{Fungsi tindak tutur Thank dengan maksud rasa terima kasih}

\section{Data 2}

Jintan : つてうか...母ちゃんの事覚えててくれたんだな。ありがとうな.

Tteika okachan no koto oboete kuretandana. Arigatouna

Jadi itu , terima kasih sudah mengingat hal-hal tentang ibuku

Menma:でも、ロケット花火ってきっといっぱいお金かかるんでしょ

Demo, roketto hanabitte kitto ippai okane kakarundeshou

Tapi, untuk membuat roket kembang api membutuhkan uang yang banyak kan

Jintan : まかせなさい

Makasenasai

Serahkan semua padaku

Data 2 merupakan tindak tutur yang bermaksud mengucapkan terima kasih. Hal tersebut dapat ditinjau dari konteks tuturan yaitu ketika Jintan sepulang dari kediaman rumah Menma untuk mencari informasi dari orang tuanya. Saat Jintan sampai dirumah tibatiba arwah Menma muncul dan mengingatkan hal-hal dulu kjetika bersama ibunya Jintan. Pada tuturan /okachan no koto oboete kuretandana, arigatouna/ yang berarti 'terima kasih sudah mengingat hal-hal tentang ibuku'. Merupakan tindak tutur ekspresif dengan fungsi apologies dengan maksud terima kasih.

\section{Fungsi tindak tutur sympathy dengan maksud penyesalan}

\section{Data 3}

Anaru : 言ったよな!!

Ittayona!!

Sudah kubilang!

Jintan : おえ 何してんだ?

Oee nani shitenda

Oii apa yang kamu lakukan ?

Anaru：あの日も、本当は言って欲しいくなかった。

Ano hi mo, hontou wa itte hoshii kunakatta

Saat hari itu juga sebenarnya aku tidak ingin kau pergi

Jintan：あの日て? 


\section{Ano hi te?}

Hari itu?

Anaru：あたし今から通告、通告性格悪いこと言いうよ。ジンタンあの時メンマに好きじゃ ないって言った。あたし最低だけどちょっと嬉しかったんだ。あれからずっと痛い、 あの時あの一瞬嬉しくなっちゃった自分を許せなかった。ずっと絶対許せなかった Atashi ima kara tsuukoku, tsuukoku seikaku warui koto iiuyo. Jintan ano toki Menma ni suki jaanai itte itta. Atashi saitei dakedo chotto ureshikattanda. Are kara zutto itai, ano toki ano isshun ureshiku natchatta jibun wo yurusenakatta, zutto zettai yurusenakatta.

Saat itu aku, mengatakan hal yang sangat buruk. Pada saat Jintan mengatakan tidak menyukai Menma. Aku memang brengsek yang saat itu sedikit senang. Sejak saat itu terasa menyakitkan, saat itu aku tidak bisa memafkan diriku yang senang walaupun sedikit saja. Aku tidak pernah bisa memafkan diriku sendiri. ( Sambil menangis keras)

Jintan：お客さん、来たからさ

Okyakusan, kita karasa

Ada pembeli datang

Anaru : お願いかないたら、メンマいなくなちゃんじゃあないの?

Onnegaikanai tara, Menma inakuna chan jaa nai no?

Setelah permohonan Menma terkabul, apakah Menma akan menghilang ?

Tuturan pada data 3 merupakan tuturan ekspresif dengan maksud penyesalan. Dapat ditinjau melalui konteks tuturan ketika Anaru melihat Jintan yang lagi sedang mempersiapkan untuk kerja. Anaru dengan nada yang keras serta sambil memegang pundak Jintan. Saat itu juga tiba-tiba Anaru teringat dengan perkataannya yang dulu semasa kecil, saat bertanya kepada Jintan apakah menyukai Menma? yang mengakibatkan temannya kesal dan berakata kasar lalu berlari kedalam hutan hingga terjatuh. Pada tuturan I Atashi ima kara tsuukoku, tsuukoku seikaku warui koto iiuyo. Jintan ano toki Menma ni suki jaanai itte itta./ merupakan jenis tuturan deklaratif (pernyataan) merupakan fungsi tuturan ekspresif sympathy dengan maksud penyesalan.

\section{Fungsi tindak tutur atittudes dengan maksud mengejek dan menyalahkan}

\section{Data 4}

Anaru： 居たなら声かけてくれればイイのに Itanara koe kakete kurereba ii no ni

Kau disini, kenpa kau tidak menyapaku !

Tsuruko： 緑高の子と一緒にいるとこ誰かに見られたら恥ずかしいしね Midori no ko to issho ni iru toko, dareka ni mi raretara hazukashīshi ne Aku malu dilihat berteman dengan anak kampung

Anaru： ハアいつからそんな偉そうになったのアンタロ前はもつとおどうどう託せん Haa! itsukara son'na era-sou ni natta no anta mae wa mottoodou dou takusen Sejak kapan kau bertingkah seperti ini, padahal kau dulu adalah orang yang sangat peduli

Tsuruko：ある意味そっちは変わってないわね。昔から人に影響されやすくて、一緒に いた股の緩そうな女にそっくり 
Aru imi socchi wa kawattenai wane. Mukashi kara hito ni eikyou sareyasukute, issho ni ita mata no yura souna onna ni sokkuri

Artinya kau sampai saat ini tidak berubah ya. Sejak dulu selalu mudah di

pengaruhi oleh orang lain sangat mirip dengan wanita itu

Anaru : ちょっと!!

Chotto!

Hei !

Tuturan pada data 4 merupakan tuturan eksprersif dengan maksud mengejek yang dapat ditinjau dari konteks yaitu ketika saat Anaru dan Tsuruko berada di tempat yang sama untuk membicarakan sesuatu. Saat itu Anaru menghampiri Tsuruko yang tidak menyapanya padahal dulu adalah teman yang sangat dekat. Melihat hal tersebut Anaru sangat marah dan berniat untuk berbicara dan menanyakan dengan baik.

Pada tuturan /Midori no ko to issho ni iru toko, dareka ni mi raretara hazukashīshi ne/ yang berarti 'aku malu dilihat berteman dengan anak kampung' yang merupakan fungsi tindak tutur atittudes dengan maksud mengejek. Pada tuturan Midori no ko to issho ni iru toko, dareka ni mi raretara hazukashīshi ne/ secara langsung memiliki maksud mengejek penutur karena bersikap seperti anak kampung lalu bersekolah di tempat yang tidak terkenal dan selalu menyombongkan dirinya.

\section{Data 5}

Yukiatsu : 王大付属の試験に失敗して、すべり止めの緑高も行かずにお家でシコシコ本 間メイコの妄想か。

Oudai fuzoku no shiken ni shippai shite, suberi dome no midorikou mo ikazu ni oie de shikoshiko Honma Meiko no mousouka

Kau khwatir ya dengan ujian sekolah, kau bahkan tak sekolah hanya dirumah saja, dan berkhayal tentang Honma Meiko kan ?

Popo ：そう言う方悋だろう、リーダーに向かって

Sou iu katane darou, riidaa ni mukatte Jangan bilang begitu, di depan pemimpin

Yukiatsu : 超平和バスターズのうか

Chou hiewa basutazunoka

Ketua perdamaina super busters ya?

Popo : そうだよ

Soudayo

lya!

Yukiatsu : なら言わせて貪うけど、メンマが死んだあの日。俺たち平 和をバスターしたの はだれだっけ?なあ....リーダー

Nara iwa sete moraukedo, Menma ga shinda ano hi. ... Oretachi no heiwa o basutā shita no wa dareda kke? Naa. ... Riidaa

Kalau begitu beritahu kami, saat menma mati hari itu. siapa ya yang bilang kalau kita ini perdamaian super busters ? iyaa ketua ? ( sambil menatap wajah Jintan)

Jintan : (hanya terdiam dan menahan air mata )

Pada data 5 merupakan tindak tutur ekspresif yang bermaksud menyalahkan. Hal tersebut dapat ditinjau dari konteks ketika saat sedang Jintan datang untuk memenuhi permintaan temannya dan membicarakan soal permohonan terakhir sahabat kecilnya yaitu 
Menma yang telah lama meninggal. Jintan yang bertemu teman-temannya malu karena hanya dirinya yang tidak sekolah dan menjadi seseorang yang hanya mengurung diri di rumah saja.

Pada tuturan /Nara iwa sete moraukedo, Menma ga shinda ano hi. ... Oretachi no heiwa o basutā shita no wa dareda kke? Naa. ... Riidaa/ yang berarti 'Kalau begitu beritahu kami, saat menma mati hari itu. siapa ya yang bilang kalau kita ini perdamaian super busters ? iyaa ketua ?' merupakan fungsi tuturan ekspresif atittudes dengan maksud menyalahkan. Tuturan /Nara iwa sete moraukedo, Menma ga shinda ano hi. ... Oretachi no heiwa o basutā shita no wa dareda kke? Naa. ... Riidaal secara tidak langsung memiliki maksud menyalahkan mitra tutur karena ulahnya dulu sebagai ketua tidak bisa melindungi temannya satu sama lain dan berbohong tentang perasaanya sendiri.

\section{Fungsi tindak tutur greetings dengan maksud permohonan Data 6}

Jintan：俺だけじゃなくて、皆んなとちゃんと喋りたいって、だからだから成仏して 生まれ変わりたいって、あいつは皆んなに見つけて欲しいんだよ

Ore dake janakute, min'na to chanto shaberitai tte,dakaradakara jōbutsu shite umarekawaritai tte, aitsu wa min'na ni mitsukete hoshī nda yo

Bukan aku, Menma sebenarnya ingin berbicara dengan kalian maka dari itu dia ingin istirahat dengan tenang, dan untuk terlahir kembali, dia ingin kalian semua menemukannya.

Yukiatsu：メンマの願いちゃんと叶えよう。メンマも呼んで一緒に

Menma no negai chanto kanaeyou. Menma mo yonde issho ni

Mari kita kabulkan, permohonan Menma, Kita panggil Menma dan

mengabulkannya bersama

Anaru：そうだよメンマ抜きで話したって意味ない

Soudayo menma nuki de hanashitatte imi nai

Benar, kalau kita tidak bicara kepada Menma, tidak ada artinya

Tsuruko：私たち六人で、超平和バスターズだから。

Watashitachi roku nin de, chou heiwa basutāzudakara

Kita ini 6 orang kan ? dan kita ini satu perdamaian super busters kan ?

Popo：だような、だようなジンタン

Dayouna, dayouna Jintan

Benar, benar kan Jintan?

Pada data 6 merupakan tindak tutur ekspresif dengan maksud permohonan. Hal tersebut dapat ditinjau dari konteks ketika Jintan sepulang kerumah menemukan arwah Menma yang jatuh dan terbaring di lantai. Melihat hal tersebut Jintan langsung berlari dan bergegas untuk bertemu dengan teman-temannya

Pada tuturan Iminna to chanto shaberitai tte,dakaradakara jōbutsu shite umarekawaritai tte, aitsu wa min'na ni mitsukete hoshiinda yol yang berarti 'Menma sebenarnya ingin berbicara dengan kalian maka dari itu dia ingin istirahat dengan tenang, dan untuk terlahir kembali, dia ingin kalian semua menemukannya' merupakan fungsi tuturan ekspresif greetings dengan maksud permohonan. Tuturan /minna to chanto shaberitai tte,dakaradakara jōbutsu shite umarekawaritai tte, aitsu wa min'na ni mitsukete hoshiinda yol secara langsung memiliki maksud permohonan Jintan kepada temantemannya untuk menemukan dimana terakhir Menma terjatuh serta memanggil namanya agar arwah Menma bisa tenang dan terlahir kembali. 


\section{Fungsi tindak tutur wishes dengan maksud mengharapkan}

\section{Data 7}

Yukiatsu：なあ!! メンマに会いたくないのか。俺会いたくてさあお前らだって会いたかった んだろ?だから会わせてやろうと思ってさ

Naa !! Menma ni aitakunai nouka. Ore aitakutesaa, omaera date aitakattan darou ? dakara iwasete yarou to omotesa

Hei !! kau bertemu dengan menma kan ? aku juga sangat ingin bertemu dengannya, kalian semua juga ingin bertemu kan ? oleh karena itu aku melakukan hal ini

Jintan : ユキアツ

Yukiatsu

Yukiatsu ( Jintan merasa takut dan terjatuh)

Yukiatsu : なのに...なのになんでおまえだけメンマがみえるんだよそんなの怖いじゃねかよ

Nano ni... nano ni nande omae dake Menma ga mierun dayo, sonna no kowai jane kayo

Tapi.., tapi kenapa hanya kau saja yang bisa melihat Menma, dan kau pun tidak merasa takut!

Jintan：それは多分彼奴は俺恨んでるが

Sore wa tabun aitsu ha ore oranderu ga....

Itu, mungkin karena dia dendam pada...

Yukiatsu : だたらお前より俺の前に出てくるはずだろう、あの日俺が案内こと言わないき やあ。

Datara omae yori ore no mae ni detekuru ha hazu darou, ano hi ore ga annai koto iwanai kyaa.

Kalau begitu, seharusnya dia datang kepadaku!. Pada hari itu kalau aku tidak berkata seperti itu

Pada data 7 merupakan tindak tutur ekspresif dengan maksud mengharapkan. Hal tersebut dapat ditinjau dari konteks saat Yukiatsu menyamar menjadi Menma dan berlari kedalam hutan. Saai itu Yukiatsu terjatuh dan ketahuan dengan teman-temannya bahwa ia menyamar menjadi arwah Menma dengan menggunakan pakaian yang sama dengan Menma saat sewaktu kecil. Yukiatsu yang merasa marah langsung menarik dan menjatuhkan Jintan kebawah. Pada tuturan / Naa !! Menma ni aitakunai nouka. Ore aitakutesaa/yang memiliki arti 'Hei !! kau bertemu dengan menma kan?' yaitu fungsi tuturan ekspresif wishes dengan maksud mengharapkan.

\section{Fungsi tindak tutur challenges dengan maksud menentang}

\section{Data 8}

Jintan

$$
\text { :メンマの幽霊 }
$$

Menma no yuurei

Hantu Menma

Popo：でした。何かめんまが俺たちに願いこと叶いと死んだって、だからいくつ書 限ら し見たんだ。

Deshita. Nanka Menma ga oretachi ni negai koto kanai to shindatte, dakara ikutsuka kagirashi mitanda 
Terus. Sepertinya, Menma ingin kita mengabulkan permohohannya pada saat kematiannya, Jadi aku tulis beberapa permohonanya disini

Yukiatsu : 曜日高行<や

Youbikou ikuya

Aku bersiap-siap pergi ke sekolah

Tsuruko

: $\frac{\text { 幽霊とうかそう言うたファンタジ嫌いなんと! }}{\text { Yuurei touka sou iuta fantajii kirai nanto! }}$

Hantu, ilusi atau apa yang kau katakana aku sangat membencinnya !

\section{Simpulan dan saran}

Berdasarkan hasil penelitian yang membahas tentang fungsi dan maksud tuturan pada film Ano Hi Mita Hana ditemukan fungsi ekspresif dan maksud tindak tutur tekspresif antara lain, fungsi tuturan ekspresif (1) apologies (permintaan maaf) yang disajikan dalam maksud meminta maaf (2) thank (mengucapkan terima kasih) disajikan pada maksud terima kasih atau bentuk sopan penutur kepada mitra tutur (3) sympathy (bersimpati) disajikan pada maksud penyesalan, (4) attitudes (menyatakan sikap) disajikan pada maksud mengejek, menyalahkan (5) greetings (mengucapkan salam) disajikan dengan maksud permohonan, (6) wishes (menyampaikan harapan) disajikan pada maksud menyampaikan harapan (7) challenges (pertentangan) yang disajikan pada maksud menentang. Dalam penjelasan tersebut dapat diketahui bahwa terdapat 7 fungsi tindak tutur ekspresif dan 8 maksud tindak tutur ekspresif yang terdapat dalam film Ano Hi Mita Hana.

Fungsi tindak tutur yang sering muncul antara lain thank, sympathy dan atittudes dengan maksud tuturan yang yang sering muncul seperti halnya menyatakan maksud meminta maaf, berterima kasih, mengungkapkan. Pada saat orang Jepang saling berkomunikasi memiliki maksud dan tujuan yang berbeda jika diutarakan secara langsung, orang Jepang memiliki cara atau strategi tuturan agar lawan penutur tidak tersinggung atas ucapannya.

Dengan adanya penelitian mengenai gambaran penggunaan fungsi dan maksud tindak tutur ekspresif dalam film Ano Hi Mita Hana , maka dapat disarankan beberapa hal sebagai berikut. Agar nantinya calon pengajar, dapat memberikan proses pembelajaran yang menggunakan media drama, anime atau film dalam pembelajaran bahasa Jepang. Melalui pembelajaran tersebut dapat mengenal mengenai tuturan-tuturan ekspresif bahasa Jepang secara langsung dengan fungsi dan maksud yang berbeda-beda. Selain mempelajari mengenai tuturan ekspresif bahasa Jepang juga dapat mengenal budaya masyarakat Jepang.

\section{Daftar Pustaka}

Austin, J.L. 1995. How To Do Things with Word. London : Oxford University Press.

Astawa, P.Y. 2013. Tindak Tutur Ekspresif Dalam Film My Boss My Hero. Jurusan Pendidikan Bahasa Jepang. Universitas Pendidikan Ganesha.

Carretero, M., dkk. 2015. An analysis of expressive speech acts in online taskoriented interaction by university students. Procedia social and behavioral sciences, (hlm.186190). 
Dyah, W. 2015. Permohonan Maaf Dalam Film Ichi Rittoru No Namida: Kajian Kesantunan Berbahasa. Volume. 5, Nomor 2.

Koizumi, T. 1993. Nihongo kyoushi no Tame no Gengogaku NyuumonTokyo Taishukan Shoten.

Leech, G. 1993. Prinsip-Prinsip Pragmatik (diterjemahkan oleh Oka). Jakarta: Universitas Indonesia.

Marwanti, D. 2013. Tipe dan Maksud Tindak Tutur Ekspresif Dalam Komik Spirouet Fantasio Karya Andre Franquin. Skripsi (tidak diterbitkan) Program studi Pendidikan Bahasa Prancis, Universitas Negeri Yogyakarta.

Searle, J.R. 1979. Exspression and Meaning. New York: Cambridge University Press.

Yule, G. 2006. Pragmatics (diterjemahkan oleh indah).Yogyakarta: Pustaka Belajar

Tarigan, H.G. 1986. Pengajaran Pragmatik. Bandung: Angkasa. 